1 Unidade Básica de Saúde ESF Parque Esperança I - Duque de Caxias (RJ), Brasil.

2 Unidade Básica de Saúde ESF Walter Ayres - Patos (PB), Brasil.

${ }^{3}$ Sindicato dos Agentes Comunitários de Saúde e Agentes de Combate às Endemias de Patos e Região (Sindacse) - Patos (PB), Brasil.

${ }^{4}$ Clínica da Família Valter Felisbino de Souza - Rio de Janeiro (RJ), Brasil.

5 Sindicato dos Agentes Comunitários de Saúde do Municí́io do Rio de Janeiro (Sindacs-RJ) - Rio de Janeiro (RJ), Brasil.

6 Fundação Oswaldo Cruz (Fiocruz), Escola Nacional de Saúde Pública Sergio Arouca (Ensp), Centro de Saúde Escola Germano Sinval Faria (CSEGSF) - Rio de Janeiro (RJ), Brasil. jasnadais@gmail.com

${ }^{7}$ Comissão dos Agentes Comunitários de Saúde de Manguinhos (Comacs) -

Rio de Janeiro (RJ), Brasil.

\section{Avançando na construção do SUS: propostas políticas a partir da atuação de Agentes Comunitários de Saúde}

\author{
Advancing in SUS construction: political proposals based on the work \\ of Community Health Workers
}

Andrea Gomes Siqueira1, João Bosco Eleutério de Assis, 2,3, Wagner Souza ${ }^{\mathbf{4}, \mathbf{5}}$, Jorge Antônio dos

Santos Nadais ${ }^{\mathbf{6}} \mathbf{7}$

DOI: $10.1590 / 0103-110420195824$

O CENÁRIO ATUAL, DE DESCONSTRUC̣ÃO DA PROTEC̣ÃO SOCIAL no Brasil, nos provoca a olhar nossa trajetória de luta pelo direito à saúde e a construir novas formas de fortalecimento do Sistema Único de Saúde (SUS). Talvez seja momento de reconhecer as propostas e reflexões políticas atuais de um grupo de trabalhadores que atuaram nos debates da Reforma Sanitária dos anos 1970, mas tiveram sua participação ocultada na história tradicionalmente contada: os agentes de saúde, mais tarde regulamentados e reconhecidos como Agentes Comunitários de Saúde (ACS).

São trabalhadores exclusivos do SUS que atuam próximos da população usuária e destinatária do direito à saúde. Inserem-se duplamente no sistema, como usuários e trabalhadores, e encontram-se em um ponto estratégico para pensar uma Reforma Sanitária capaz de transformar efetivamente a vida das pessoas.

O entrevistador, Jorge Nadais, é um dos membros fundadores da Comissão dos ACS de Manguinhos (Comacs), comunidade do município do Rio de Janeiro, onde atua como ACS há 6 anos. Os entrevistados são: Andrea Siqueira, ACS no município de Duque de Caxias no Rio de Janeiro (RJ) há 13 anos; João Bosco, presidente do Sindicato dos Agentes Comunitários de Saúde e Agentes de Combate às Endemias de Patos e Região (Sindacse) e atuante como ACS há 28 anos no município de Patos na Paraíba (PB); e Wagner Souza, Técnico ACS, vice-presidente do Sindicato dos Agentes Comunitários de Saúde do Município do Rio de Janeiro (Sindacs-RJ), município onde atua há 15 anos. O ACS é território, e uma verdadeira Reforma Sanitária se faz pelo território, na relação com o usuário.

JORGE: Muito se fala da participação de médicos sanitaristas na Reforma Sanitária, mas há pouco registro da participação de nós, ACS, nessas discussões. Também são aqueles profissionais que, geralmente, são ouvidos nas avaliações e revisões críticas do processo de construção do SUS. Esta entrevista tem como objetivo primordial buscar a percepção dos ACS, de diferentes localidades, com relação ao que tem sido feito do SUS e perguntar: o que temos hoje pode ser melhorado? Vamos iniciar a conversa pela nossa representante mulher. Andrea, fale da sua trajetória como ACS. 
ANDREA: Eu estou há 13 anos agente comunitária pelo município de Duque de Caxias, RJ. Quando fiz o processo seletivo, a chamada era feita nos bairros, nas praças, igrejas. Como eu já trabalhava como voluntária da Pastoral da Criança, me interessei em fazer o processo, e desde então estou na mesma microárea. São 13 anos de convivência com as pessoas com quem comecei a trabalhar, vendo os filhos crescerem.

BOSCO: Eu sou ACS em Patos, quinta maior cidade da Paraíba, com 110 mil habitantes, desde 1991. Sou da primeira turma de ACS na Paraíba. Foi um processo seletivo feito pelo estado em parceria com os municípios e com o Ministério da Saúde (MS). Em 1991, Patos era uma cidade extremamente necessitada de infraestrutura social, tanto no campo da saúde quanto na educação, na assistência social. Então, o Programa de Agente Comunitário de Saúde (Pacs) veio para modificar aquela realidade de uma cidade cravada no sertão nordestino e que passava por diversos problemas de vulnerabilidade social. Especificamente na comunidade Noé Trajano, que é extremamente carente, como o restante da cidade, procuramos fazer esse diagnóstico. O trabalho de um ACS não é e nunca foi só o da Visita Domiciliar (VD). O nome da profissão, Agente Comunitário de Saúde, traz a essência do trabalho dele: é selecionado do seio da comunidade alguém que se identifica e que pode trabalhar conjuntamente com essa comunidade para modificar situações de vulnerabilidade social. Nosso foco é trabalhar as condicionantes para melhorar a promoção e prevenção de saúde da população para o qual a gente está adscrito. Jamais nós podemos atuar na cura da doença.

WAGNER: Fiz um processo seletivo amplo, que mobilizou mais 170 mil candidatos no município do Rio de Janeiro. Atuo desde 2003, fiz 16 anos agora. A gente não conhece a realidade de onde mora quando inicia esse trabalho. Sou morador e atuo no Complexo do Alemão, que é uma das maiores favelas do estado do RJ. Tem em torno de 180 mil pessoas. A minha unidade tem aproximadamente 32 mil cadastrados. A gente tem uma área muito grande, muito densa, com as realidades sociais diversas e desafios enormes. Em 2003, quando eu comecei a enxergar a realidade do local onde eu moro, vi as necessidades da população; e, com isso, nos inquietamos para tentar melhorar e buscar alternativas, mobilizar essa população, que é uma das coisas mais difíceis do mundo: fazer com que o povo entenda que ele é o ator daquilo ali, que ele pode mudar. Esse é um dos pilares da atuação do ACS. A Saúde da Família dentro do Complexo do Alemão foi o primeiro equipamento público, além da polícia, a atuar no território. Era um imenso deserto sanitário. Para tomar uma vacina, a gente andava em torno de seis a sete quilômetros. E com a Saúde da Família, trouxemos uma realidade sanitária para dentro do Complexo com uma proposta diferente, de promoção e de prevenção, que a gente foi perdendo por causa das políticas públicas que vieram. Aí a gente passou a ser números, infelizmente, e deixamos de lado a questão da nossa essência, que tentamos resgatar a todo instante. Os colegas entram trabalhando sem curso introdutório. A gente que está no campo há mais tempo é que ensina como fazer, mas esse colega não tem uma bagagem para fazer o trabalho do ACS. Ele vai na coleta de dados, vai visitar um morador, mas simplesmente só pergunta “como você está". Ele não observa o ambiente, não observa a casa porque ele não foi treinado, ele não tem esse olhar diferenciado como se tinha antigamente. Temos que tentar resgatar nossa essência via Confederação Nacional dos Agentes Comunitários de Saúde (Conacs), via sindicatos nas suas bases, junto aos gestores, porque a população necessita desse olhar diferenciado do ACS.

JORGE: Qual o desafio de ser ACS nos dias de hoje?

Bosco: Eu me apaixonei pela profissão no decorrer do aprendizado do trabalho. Nós tivemos um curso introdutório de dois 
meses, que é um curso base de formação do ACS. Nas turmas novas que estão entrando, isso não está acontecendo. O processo de ingresso de um ACS se aperfeiçoou até pela própria legislação. A Lei $\mathrm{n}^{0} 11.350^{1} \mathrm{e}$ a Emenda Constitucional $51^{2}$ nos habilitou a sermos servidores públicos, seja municipal ou estadual, por via do processo seletivo público. Hoje, nenhum novo processo seletivo exige menos do que o ensino médio completo. Na minha época, bastava ler e escrever. Mas o que era extraído desse candidato a ACS não era saber ler ou escrever, era a capacidade para trabalhar em comunidade e ser liderança comunitária. E aí é que está a essência. Você pode ter até doutorado, mas se não tiver a capacidade de dialogar, de participar de uma reunião com a comunidade e, consequentemente, com outros atores das políticas públicas, então você não serve para ser ACS. Aquela formação do introdutório visava isso. Com o avanço da universalização e da descentralização, o processo de trabalho do ACS foi sendo aperfeiçoado, e hoje realmente precisa ter ensino básico. Foi a primeira turma, de 25 ACS em Patos, uns com saberes a mais, outros com saberes a menos, que, por exemplo, venceu a cólera com um simples "dá licença, moça". Para entrar na casa da dona Maria e dizer a ela que "se ela e a família tiverem higiene pessoal e ambiental na sua residência, lavarem as mãos após todas as necessidades especiais", foi preciso muita identidade com as comunidades periféricas e de baixo nível de escolaridade. Então, em menos de seis meses, Patos deixou de ter casos de cólera. Claro que não só foi isso. Foi também influindo a comunidade, buscando se organizar junto a essa população. Com a Lei Municipal $\mathrm{n}^{\circ} 2.107^{3}$, de 15 de setembro de 1994, houve a criação dos Conselhos Municipais de Saúde (CMS). Quando foi criado o CMS em Patos, isso foi ideia nossa. Patos, naquela época, só tinha 1 associação de moradores. Hoje tem 48 . Isso é fruto do trabalho do ACS, porque nós acreditávamos que era preciso organizar a população em seus territórios para o enfrentamento de realidades perversas. A luta pelo saneamento básico da cidade, que estava caótico, passou por essa discussão. Outra virtude alcançada, que é uma vertente importante do trabalho do ACS e do Agente de Combate às Endemias (ACE), é a redução da mortalidade infantil, que era quase 100/1.000 nascidos e hoje está em 20/1.000. Mas apesar dos avanços, eu faço uma crítica a uma mudança no trabalho do ACS: muita ficha, muita burocracia fez a gente perder essa identidade do cuidado. $\mathrm{E}$ é por isso que doenças que nós conseguimos erradicar nos anos 1990 e 2000 estão voltando, como o sarampo. Os gestores querem mais números do que propriamente um trabalho de cuidado com eficiência.

ANDREA: Quando eu entrei, eu não sabia o que era ser ACS. Eu nunca tinha ouvido [falar] no programa. Eu fiz o processo seletivo porque alguém falou "ah, vai trabalhar com a comunidade" e era uma coisa que eu gostava, já fazia voluntariamente, e pensei "se me pagarem para fazer, melhor". Como eu sempre gostei de educação e eu queria ser professora, quando falaram que era para trabalhar com educação em saúde, eu me interessei. Então eu achava que era o mundo ideal: eu ia cuidar das pessoas, eu ia fazer educação. Mas hoje em dia a gente vive uma situação tão difícil que ser ACS é viver no limite. Você adoece, você não consegue cumprir. A gente deixou de trabalhar com o lado humano da prevenção e só fica gerando números e números e sofre desgaste o tempo todo. Esse é o desafio de ser ACS hoje. Tentar não descaracterizar tanto a profissão, respeitando o que foi criado lá no início, a promoção e o cuidado da saúde, aliando com as tecnologias modernas; porque eu gosto da tecnologia, eu adorei a ideia de trabalhar com tablet, de ter um computador, mas aliar as duas práticas, eu acho que esse é o nosso desafio. Fora os outros, a questão mesmo da categoria, de salário, de estabilidade, porque o Brasil todo tem ACS em situações diversas. Mas na questão do trabalho 
em saúde, eu acho que o nosso desafio é aliar as tecnologias e as inovações que vêm, sem deixar esse olhar mais sensível com a população que a gente bate na porta; porque a população nem bate na nossa porta, a gente é que bate na porta deles.

WAGNER: Acho que ser ACS tem duas vertentes hoje em dia: uma é quando você atua na microárea, em contato com a população que você escuta, troca ideia, troca seus saberes, orienta, e é orientado. E a outra é a parte burocrática do trabalho, que está nos prendendo muito mais hoje do que as visitas domiciliares. Quando você está no campo, o trabalho é dinâmico e prazeroso, e quando está na unidade, resolvendo questão burocrática, o trabalho é monótono, pressão em cima de pressão. A convivência entre essas duas vertentes é muito difícil.

JORGE: É muito complicado você conciliar a necessidade da população com aquilo que a gestão pública exige. Andrea, qual é a importância do ACS para a saúde da população?

ANDREA: Eu acho que o ACS é fundamental. Às vezes, a nossa população não tem uma dimensão da nossa profissão. Muitos dos ACS que estão entrando também não têm, mas a gente lida diariamente com as pessoas. Eu cansei de ouvir e algumas vezes eu me revoltava, "vocêé o elo com a sua comunidade", e demorei muito tempo para entender isso dentro da questão de saúde, de ser o serviço público que está na casa das pessoas. Então a gente é importante por isso, porque a gente vai conversar com eles sobre a questão da dengue no Rio de Janeiro, Zyka, questão da vacinação. É um trabalho de formiguinha, diário, que você vai construindo nessa relação com os seus usuários. Por isso é importante manter esse vínculo com a população. Se você não consegue a confiança das pessoas, como você vai dizer dos modos de vida delas? Como você vai orientar medicação? Como você vai abordar os problemas familiares? Hoje em dia a gente tem uma questão séria de depressão, de desemprego no estado, no município, mas se a pessoa não tem confiança... Cada dia que a pessoa vai é um médico diferente. Já o ACS, não: a gente está todo dia. Então ele confia de contar os problemas, da gente até abordar e dizer: "não, você tem que procurar um médico"; porque, às vezes, nem a pessoa enxerga que está doente e precisa do serviço de saúde. Para ela, aquilo é a normalidade, e, às vezes, o ACS, no dia a dia, consegue observar isso. Parece muito pouco, mas, se for juntando o trabalho de milhares de ACS pelo Brasil afora, a gente vê os resultados que aparecem. Falando em saúde caótica, como está no Rio de Janeiro, em Duque de Caxias, ter alguém que está olhando por você, que te acompanha, é muito importante. Você vai ter uma pessoa que diz "olha, você não tomou a vacina; cuida da sua saúde; veja sua alimentação". A gente, no acompanhamento, vê o processo de saúde e doença da população. É por isso que é muito complicada essa modernização, essa burocratização do nosso serviço, de se tornar número, porque o lado da conversa, quando você tem que fazer 20, 30 visitas, produzir metas, vai ficando de lado e vai se perdendo porque você está sempre correndo.

JORGE: Ouço sempre que "uma vez ACS, sempre $A C S$ ", porque é algo que te afeta de uma forma tão profunda que modifica a tua forma de ver e compreender o mundo, as políticas públicas de saúde, de meio ambiente, de educação e outras.

WAGNER: Ser ACS leva você a compreender o ser humano melhor. Você desmistifica tantas questões, tantos preconceitos, que acho que a gente se torna um ser humano melhor.

BOSCO: Após a Constituição de 1988, foi organizado todo o arcabouço jurídico do SUS, com as Leis Orgânicas da Saúde. A ideia do ACS veio para destravar o que vinha acontecendo antes: a promoção da doença em detrimento da prevenção e da promoção da saúde. A população buscava o serviço depois de adoecer. Hoje, não. Com o ACS, o sistema vai na casa de dona Maria, de seu José perguntar sobre 
as suas condições de saúde, o que é que está ocorrendo enquanto condicionante de saúde naquela residência, naquele território, para, daí, junto com a equipe multiprofissional, pensar as estratégias de cuidado pelo serviço. Por isso o ACS foi o alicerce para o modelo do SUS que temos hoje. O SUS avançou consideravelmente, mas precisa se aperfeiçoar: ser financiado melhor, valorizar o profissional, do ACS até o médico. Quando o Pacs foi implantado lá em 1991, pelo MS, ele ia trabalhar essas condicionantes de vulnerabilidade social da população. Isso partiu das experiências exitosas no Ceará. Nós, na Paraíba, no ano de 1991, passamos seis meses sem receber um centavo de salário. Mas a resposta que nós demos, por exemplo, à cólera, fez com que o governo revisse a proposta de acabar com o programa, que na época tinha uma duração de seis meses. Depois isso mudou definitivamente com a transformação dos ACS e ACE em servidores públicos reconhecidos pela Constituição Federal, e com as atribuições definidas na Lei $\mathrm{n}^{\mathrm{o}} 13.595^{4}$, Lei Ruth Brilhante. Foi preciso o ACS mostrar o seu processo de trabalho. O SUS ainda precisa avançar mais. Mas qual é o entrave? Gestores não são comprometidos com essa política pública. É uma questão de condições de trabalho. Eu passei 16 anos para receber minha portaria de efetivação como servidor público. O ACS tem que lutar para dar condições de promoção e prevenção de saúde à comunidade, mediante seu trabalho, e, ao mesmo tempo, tem que lutar pela sobrevivência do seu emprego e pelos seus direitos trabalhistas. Aqui em Patos, nós temos todos os direitos: plano de carreira e salário, piso nacional salarial, insalubridade, gratificação de carreira e efetivação pelo poder público. O ACS nunca deveria ser terceirizado ou contratado por excepcional interesse público. Ele tem que ser efetivo direto do ente federado, do estado ou município. Na Conacs, nós estamos encampando todas essas lutas. Através de mobilização, paralisação e um trabalho junto ao parlamento. Vale uma ressalva: com todos os problemas que o parlamento brasileiro tem, nós já derrubamos mais de oito vetos presidenciais. Já teve líder do governo dizendo que não vota contra o ACS. No cenário social, político e econômico que estamos vivendo, é preciso muita luta.

JORGE: Nós somos uma categoria cuja existência é vinculada à existência do SUS e que recebeu a responsabilidade da consolidação dos princípios do sistema no território.

WAGNER: Nós temos um papel muito importante na saúde da população. A questão não é só agendar consulta, não é só fazer a promoção da saúde. É trabalhar os determinantes de saúde daquela população. Dialogar com aquela população sobre o que afeta ela no seu dia a dia: a ausência de saneamento básico, a questão da água que ela bebe, as questões de moradia. E buscar alternativas e soluções. Informar a essa população que ela tem direitos, e que é o ator principal daquele local. Acho que um dos nossos papéis é esse: empoderar a população e buscar soluções junto aos poderes públicos. Às vezes, são questões que afetam a saúde naquele local e que a gente mesmo pode resolver juntando a população. Então o ACS é um agente de transformação.

JORGE: Talvez seja a categoria que conhece no seu DNA a questão da determinação social em saúde, porque ela vive a determinação social em saúde o tempo inteiro, a partir do momento que o ACS é morador e vive a realidade que afeta os seus vizinhos. É uma dupla afetação. Andrea, como é trabalhar com saúde no território em que você vive?

ANDREA: Inicialmente, a grande dificuldade foi deixar de ser apenas a vizinha, a amiga, e ser também uma trabalhadora da saúde. Até eu mesma me colocar nesse lugar foi difícil; porque, enquanto vizinha, a gente até tem a amizade e a intimidade, mas também tem um limite que precisa ser respeitado enquanto representante do Estado no território. E trabalhar no território hoje em dia está mais difícil ainda. 
A gente tem a questão da violência agravada no Rio de Janeiro. Minha área é em um bairro até tranquilo, mas não deixa de ser afetado pela violência do entorno, pelas coisas que acontecem no Rio de Janeiro de forma geral. A condição social mesmo, das pessoas, foi agravando muita coisa. Conforme isso vai piorando, vai ficando mais difícil também você trabalhar no território. Mais pessoas desempregadas, mais pessoas doentes. Quando eu comecei, meu território tinha uma peculiaridade: tinha muitos idosos. Então era um trabalho mais voltado para a promoção e qualidade de vida desses idosos. De um tempo para cá, meus idosos foram falecendo, e eu fiquei com uma população mais jovem. Então isso também mudou o meu processo de trabalho e a minha abordagem ao longo do período. Essa população mais jovem precisa entrar no mercado de trabalho, sofre de ansiedade, sofre com os conflitos da modernidade da juventude; mas o processo é agravado pela falta de condição geral de saúde do Rio de Janeiro. Muitas vezes, eu fico sofrendo com essa angústia, porque, às vezes, você bate na porta das pessoas oferecendo uma coisa que elas nem sabiam que precisavam, e que muitas vezes eu também não tenho como oferecer. Por exemplo, quando a gente conversa sobre saúde, identifica uma suspeita de câncer de mama, e você leva a pessoa para o ambulatório e aquilo é confirmado, e o processo do diagnóstico até o acesso ao tratamento é demorado. Você sofre junto com a pessoa porque você bateu na porta dela, você pesquisou, orientou até ter o diagnóstico, e aquela pessoa não consegue ser tratada com uma rapidez e uma eficiência que deveria ter. Isso também dificulta a nossa relação com a comunidade, porque é só o ACS ali falando, trabalhando, e, muitas vezes, eu me sinto sozinha nesse processo porque, no meu município, é muito difícil o acesso aos especialistas e aos exames de alto custo. Não é minha culpa, mas afeta o meu trabalho de uma forma muito pesada.

JORGE: Realmente, as limitações do serviço dificultam, pois sofremos 24 horas das mesmas angústias que o usuário.

WAGNER: O nosso trabalho é difícil, realmente. Existem alguns entraves que impedem a gente de dar uma resposta satisfatória àquela pessoa, e ela nos culpa, porque fomos nós que batemos na porta dela, somos nós a referência que ela tem de saúde, somos nós com quem, muitas vezes, ela tem esperança de conseguir resolver seu problema. Somos nós aquela primeira pessoa que ela vê. Então, às vezes, é muito difícil. Porém, é gratificante quando conseguimos solucionar. É bom receber aquele reconhecimento não só do dia a dia, mas pelo serviço que faz diferença na vida da pessoa. Como a gente é morador, é 24 horas... Você está no seu lazer e você é abordado por questões fora do seu horário de trabalho. Tem horário que você está num momento particular e não quer falar do trabalho, mas vêm pessoas te perguntando questões do trabalho. Eu vejo isso como uma dificuldade, mas isso prova também que você é referência. Então temos que responder da melhor forma possível, mesmo não querendo fazer isso naquele momento. Até porque nós somos profissionais, mas antes de tudo nós somos seres humanos e temos as nossas questões, os nossos problemas, e, às vezes, ninguém cuida da gente. A gente só cuida das pessoas. $\mathrm{E}$ a realidade, do dia a dia num grande complexo de favelas, é difícil. Às vezes, a gente se planeja para fazer uma VD e não consegue pela questão da violência urbana. Na minha área, por exemplo, tem uma base de UPP e duas bases de tráfico. Eu fico no meio. É uma situação complicadíssima. E os próprios moradores já nos avisam: Wagner, não vem não, está ruim aqui. Então a gente tem algumas inviabilidades pela questão da violência urbana, mas, sendo morador, você é cobrado. Me angustia muito e me magoa quando eu escuto a pessoa falar assim: "aquilo ali não presta, tem que fechar", falando da unidade de saúde. Mas quando a gente sempre serviu essa pessoa, prestava; um dia que a gente não conseguiu servir não é porque a gente não queira, é porque as condições que a gente tem de trabalho são 
ruins. Mas a população realmente não tem que entender. Os gestores públicos são realmente os grandes culpados dessa falência do sistema, que não dá uma resposta adequada para a população. $\mathrm{E}$ isso traz problema para o profissional, para o agente comunitário. No dia a dia, são colegas sendo agredidos, tanto verbalmente como fisicamente, por questões que não são culpa dele.

JORGE: A sensação que dá é que, às vezes, o sistema foi feito para dar errado, que a crise não é exceção à regra. E da perspectiva de um trabalhador que, ao mesmo tempo, é morador, ele tem esses diversos atravessamentos da miséria e da piora da qualidade de vida da população, da dificuldade quanto à construção de uma rede de saúde pública realmente efetiva e eficaz. $\mathrm{E}$ da violência, que é consequência desses retrocessos anteriores. Infelizmente, os territórios em que vivemos são feitos para ser o que eles são. Há uma construção que é anterior e uma intencionalidade para eles funcionarem da forma como funcionam.

WAGNER: A questão do vínculo também é um desafio por ser morador. Tem o morador que acha que você vai ser o fofoqueiro. Então a sua postura como profissional é que vai determinar esse vínculo. Eu chego na casa de um morador, ele vai falar daquela pessoa: " $a h$, fulana de tal não sei o quê...” Eu corto: "não, vamos falar de você..." Se a gente começar a dar trela, perdemos nossa credibilidade com aquela população.

JORGE: Eu acho que a gente vive uma cultura que é tão baseada no individualismo, que acaba dando um sentido privado para aquilo que é público, e o indivíduo não consegue te enxergar como profissional de saúde.

BOSCO: Nós, no sertão paraibano, temos uma realidade realmente diferente da de vocês no Rio de Janeiro e em outras regiões do país. Mas nós nos deparamos com dificuldades aqui também. A questão das drogas ocorre também aqui. Nós temos companheiros aqui que sentem as mesmas dificuldades que vocês sentem aí: territórios extremamente difíceis de trabalhar, porque tem alguém lá que acha que é dono do território. Não a comunidade organizada, mas alguém que não vê com bons olhos o processo de trabalho do ACS junto à comunidade mesmo ele estando identificado, mesmo ele estando dentro do próprio território onde ele nasceu. Mas o processo de trabalho aqui na nossa realidade mudou muito. Quando eu entrei, Patos tinha apenas duas unidades básicas de saúde. Hoje já são 42 unidades. Avançou muito na infraestrutura e na oferta de ações e serviços de saúde junto à população. Nós conseguimos muita coisa com participação social e junto com o CMS. A cidade tem cinco Conselhos Distritais de Saúde, e estamos organizando a criação dos Conselhos Locais de Saúde. Assim, cada unidade tem seu conselho, com participação dos usuários, dos trabalhadores, da própria gestão, para discutir o funcionamento dessa unidade e buscar caminhos com a participação da comunidade. É importantíssimo atuar com diversos atores nesse território e buscar diversas políticas públicas. A política de assistência social está aí com os Cras [Centros de Referência de Assistência Social] nos territórios. A política de educação está aí. As escolas públicas precisam também entender que elas estão no território e, portanto, tem que ter participação da comunidade também. A partir da implantação da Estratégia Saúde da Família (ESF), o ACS ficou no fim da fila. Eu sou adepto ao Saúde da Família, mas ela não pode ter esse sentido de equipe centrada no médico. Quando nós mudamos realidades aqui, nós só tínhamos uma enfermeira, instrutora e supervisora, com 25 agentes, e fizemos uma revolução no processo de saúde. Aí, hoje, nós temos Saúde da Família com uma equipe multiprofissional, nós temos o Nasf, e você não vê os avanços que houve outrora quando era só o ACS e a enfermeira. Mesmo com todo avanço na oferta de ações e serviços na atenção primária, a satisfação do usuário está aquém do processo 
que está implantado. Nós temos debatido e avaliamos que a ESF está deixando a desejar porque deixou uma equipe multiprofissional que não é da comunidade e não está inserida no território, como o ACS está, formular as suas estratégias de ações sem a participação do ACS. Ou a equipe participa do planejamento das ações e serviços, ou você não vai ter êxito nunca; você pode colocar aqui doutorados em saúde preventiva, em saúde coletiva, e não dá conta, por quê? Porque não interage com a célula principal que está inserida, que veio do seio daquele território no qual essa equipe está trabalhando. Enfim, eu acho que o saber popular e o saber científico podem se juntar e dar uma resolutividade para a problemática de saúde que nosso povo tem.

JORGE: É muito importante formarmos profissionais em Saúde da Família, porque quando foi criado o SUS, talvez não se tivesse a dimensão das necessidades de adequação da formação do profissional de saúde à realidade da população. O SUS, quando foi construído como um sistema público, foi baseado em alguns princípios e diretrizes. Para você, Andrea, de acordo com o dia a dia de trabalho, o que disso tudo foi alcançado na prática?

ANDREA: A universalidade é uma coisa que está aí. $\mathrm{O}$ acesso, às vezes, é difícil em alguns lugares, mas sendo brasileiro, estando no território, você tem acesso a algum tipo de saúde. Então eu acho que é uma questão que deu certo. A gente ainda tem defeitos, mas funciona para todo mundo. Quando é ruim, é ruim para todo mundo também.

JORGE: Nós temos uma das legislações de saúde pública mais avançadas do mundo. Em princípio, o nosso sistema é maravilhoso, ele é delicioso de ser estudado e debatido, mas eu observo que há uma diferença abissal entre a eficácia e a efetividade pretendidas e a realidade.

ANDREA: O acesso ainda não está igual. Falta integralidade, falta muita coisa. A questão da participação popular, dos Conselhos, eu acho que não caminha do jeito que foi pensado. Por exemplo, o meu município tem conselho de tudo, mas não funcionam como conselhos... É até deliberativo, mas, às vezes, fica esvaziado. A gente ainda tem que trabalhar muita coisa. $\mathrm{E}$ eu, antes, tinha uma vivência de participação política na comunidade, que se aperfeiçoou enquanto ACS; e eu acho que o caminho que a gente tem é transformar esse ser político que o ACS se torna, refletido na população dele, porque nós falamos de leis, sabemos muita coisa, vamos a muitas reuniões, mas como fazer com que a sua população seja também atuante, se responsabilize pelas questões, saiba se posicionar? Porque, às vezes, a gente vai e briga, mas eu acho que a gente tem uma tarefa de educação em saúde, tem que ensinar a essas pessoas que elas também podem falar, que elas têm ouvidorias, conselhos. Tem que ter a contribuição delas na criação desse SUS. Está ruim? Vamos conversar por que está ruim, o que está ruim, o que eu, enquanto cidadão, posso ajudar. Esse é um desafio muito grande do SUS e nosso também de ACS.

JORGE: É interessante que, quando nós falamos dos princípios do SUS, isso causa um certo estranhamento, porque, de certa forma, eles estão tão distanciados da nossa realidade, que geram aquela pergunta: ué, mas o sistema é integral realmente? Ele é universal realmente? E você começa a refletir sobre a prática.

WAGNER: Eu acho que a universalização é um dos princípios mais alcançados. A descentralização também ocorre. Os outros são parciais. A integralidade é parcial, pela dificuldade do sistema que nós temos. A equidade é uma questão que a gente não discute. Na verdade, a gente não discute os princípios do SUS no dia a dia dos profissionais. Há profissionais que nem conhecem que existem princípios do SUS, quais são, o que significam, e qual a sua importância, para atuar em cima disso. E isso vem até de gestor, não é só de quem está lá no 
dia a dia na ponta, não. Às vezes, você até faz, mas sem saber que é um princípio do SUS. A participação popular é uma questão também complicada. Às vezes, a população não quer participar de nada, porque acha que reuniões são chatas, e existe uma dificuldade de acesso aos Conselhos Distritais e Municipal de Saúde. São pessoas que estão lá se perpetuando nos conselhos, como acontece no Rio de Janeiro. Não há uma renovação. É uma dificuldade de você atuar, de ter voz e voto. Então os gestores acabam, muitas vezes, dominando esses conselhos, e, na prática, deveriam ser os usuários que são $50 \%$ do conselho.

ANDREA: No meu município também. Parece uma monarquia do conselho.

WAGNER: Os horários são complicados, geralmente meio de semana em horário de trabalho. Então fica mais difícil a participação. Eu acho que os princípios funcionam parcialmente e são importantes. Eles fazem o SUS. Temos que debater e construir políticas locais em cima desses princípios.

JORGE: É uma discussão complicada, porque há uma certa má vontade do próprio gestor público com relação ao SUS. Isso vem desde o período da Reforma Sanitária e da construção da nossa Constituinte, quando houve uma conciliação entre a visão de uma saúde pública universal e a visão de uma saúde privada, privatista. Então nem sempre há interesse do gestor na efetividade dos princípios do SUS, como ele nasceu para ser.

BOSCO: O SUS, em Patos, só tem serviços públicos de saúde. Não são serviços conveniados com o SUS ofertados por entidade privada ou filantrópica. São serviços administrados pelo estado da Paraíba ou pelo município de Patos. A atenção primária é toda municipal. Hoje o município tem a UPA [Unidade de Pronto Atendimento], tem mais três hospitais - sendo uma maternidade que é a mais bem equipada do interior do Nordeste, um hospital infantil e um complexo hospitalar regional. Essas três casas são geridas pelo governo do estado, e temos 42 unidades básicas de saúde em todo o território da cidade, que é $100 \%$ coberto pela Saúde da Família. Nós temos o Caps [Centro de Atenção Psicossocial], o Caps Infantil, o Caps AD, vigilância sanitária, o CEO [Centro de Especialidades Odontológicas], Samu [Serviço de Atendimento Móvel de Urgência], e nós temos lá no complexo regional Janduhy Carneiro um hemocentro. Nós temos a questão do pessoal de nefrologia, e nós temos hoje um hospital do câncer. Patos tem uma malha SUS pública invejável a qualquer cidade do porte dela. Por outro lado, nós temos um estado da Paraíba que não investe um centavo na atenção primária. O estado tem toda uma rede de hospitais. É uma política hospitalocêntrica. O estado tem, sim, que investir na atenção primária, porque a cada real investido na atenção primária para promover e ter a prevenção de saúde, você economiza três no tratamento da doença. E me parece que, no Brasil todo, você só tem três ou quatro estados da federação, incluindo o Distrito Federal, que investem na atenção primária. Mas apesar de Patos ter todo esse arcabouço de malha SUS, nós ainda padecemos de duas questões, que foram ponto de discussão da última Conferência Municipal de Saúde: primeiro, o esgotamento sanitário. Patos só tem $5 \%$ de esgoto tratado. E também a questão do aterro sanitário.

JORGE: Esse olhar do gestor público para a saúde pública, de forma integral, é talvez o grande desafio. A nossa realidade no estado do Rio de Janeiro é a mesma. Infelizmente, o estado não investe um centavo em atenção básica, e isso causa uma dificuldade muito grande. A justificativa recente é a queda de arrecadação do estado. Só que esse desinvestimento não é uma realidade das duas últimas gestões, é uma realidade bem anterior. O cumprimento das responsabilidades da administração pública federal, municipal e estadual talvez seja hoje um dos grandes dilemas da implementação do SUS. O sistema que foi 
construído durante as discussões da Reforma Sanitária foi para o papel de uma forma completamente diferente. Ele se tornou um híbrido das propostas que foram discutidas na época. Existia uma parcela do movimento que preconizava um sistema unicamente público. Mas, na Constituição, foi inserida a iniciativa privada como uma parceira, com atuação complementar e subsidiária ao público. Hoje chegamos ao ponto de vivermos um processo aberto de defesa, na academia, da privatização do SUS, que reflete uma espécie de privatização das mentalidades, que partem do pressuposto de que, se o SUS não funciona bem, então dá para descartar. Eu avalio que nós temos avanços com relação ao que havia na época da Reforma Sanitária. Hoje, muito se fala da necessidade de algumas correções de rota partindo do pressuposto de que nós precisamos fazer uma Reforma Sanitária. E se a Reforma Sanitária fosse nossa, o que você faria, Andrea?

ANDREA: Eu acho que o principal da Reforma Sanitária é discutir, no sentido integral de saúde, essa questão do esgoto, do lixo, do saneamento básico, que acabou ficando para trás. No Brasil, em poucas cidades, o lixo e o esgoto são tratados. Na minha, por exemplo, não existe sistema de esgoto. $\mathrm{E}$ com relação à assistência em saúde, e mais especificamente à atenção primária, eu gostaria de virar de cabeça para baixo, porque a gente acabou ficando lá atrás. Eu não gostaria de tirar a figura do médico e do enfermeiro, mas realmente fortalecer a importância do ACS, do convívio com a população. Não construir mais hospital, emergências e UPAs. Mas investir mais no saber popular, porque a gente tem muito conhecimento, a gente tinha o contato com os indígenas, o contato com os africanos. Essas coisas todas foram se perdendo nessa ideia de tudo se resolver em hospital, e acaba que toda a nossa população vai morrer na porta do hospital porque o hospital não vai resolver tudo. A atenção básica, não sei se vai resolver tudo também, mas ela pode ser muito ampliada. Por exemplo, no meu município, tem
30\% da cobertura de Saúde da Família. É um município rico que tem um hospital estadual e um municipal que não dão conta de quase 1 milhão de habitantes. Mas a ESF, se bem orientada, com investimento e organização, iria diminuir as filas nos hospitais e nas UPAs da vida. Mas é uma questão de gestão, de observar que essa população precisa ser cuidada, com um atendimento mais sério, mais diversificado e, ao mesmo tempo, mais inserido no território. Em Duque de Caxias, agora estão sendo implantadas as práticas integrativas. Eu acho um avanço você lidar com acupuntura, com cromoterapia e várias dessas alternativas. Mas se não fortalecer a atenção básica, não adianta colocar só mais uma coisa no pacote para não funcionar ou para não chegar a quem tem que chegar. Como a população vai saber dessas práticas e ter acesso, se a atenção básica não funciona como tem que funcionar? Na minha reforma, eu viraria de ponta-cabeça: vamos botar ACS bem formado, trabalhando nesse Brasilzão inteiro.

WAGNER: Se eu tivesse o poder da caneta, como disse o presidente aí, a primeira canetada seria para revogar a Emenda Constitucional 95, porque ela tira o financiamento do SUS, do social e da educação. A segunda questão é: $100 \%$ estatização do SUS, sem a participação do privado em hipótese nenhuma. A gente não necessita do privado. $\mathrm{O}$ financiamento tem que ser eficiente, com a participação popular. Os gestores públicos deveriam decidir as políticas públicas junto com a população, discutindo como e onde vai gastar cada centavo.

JORGE: Wagner foi profundo e conciso na raiz do problema. E para você, Bosco, se a Reforma Sanitária fosse sua, o que você faria?

BOSCO: Nós perdemos oportunidades nesses últimos anos. Já está definido que municípios e estados devem gastar com saúde, respectivamente, $15 \%$ e $12 \%$ de seus orçamentos. No entanto, o ente federativo que mais arrecada 
*Orcid (Open Researcher and Contributor ID). impostos da população, que é o governo federal, não gasta mais de $4 \%$ do seu orçamento com saúde. Tivemos a oportunidade, no então governo Dilma, quando foi sancionada a Lei Complementar $n^{\circ} 141$ de 2012 que regulamentou a Emenda Constitucional 29, de comprometer $10 \%$ do orçamento federal com a saúde. Mas isso não aconteceu. Além disso, houve um projeto de lei de iniciativa popular pedindo $10 \%$ do orçamento federal para saúde, que foi entregue pelo Conselho Nacional de Saúde ao então deputado Eduardo Cunha, e que foi vetado no Congresso. O SUS já era subfinanciado e continuou a sangrar ali, porque não tem sentido um sistema público de saúde num país continental como o nosso, subfinanciado dessa forma. Isso é um dos primeiros gargalos que eu acho que uma nova Reforma Sanitária precisa resolver para melhorar o sistema: o subfinanciamento. Segundo, o fortalecimento do sistema passa pelo investimento maciço, dos três níveis de governo, na atenção primária. A atenção primária é a porta de entrada do sistema. Isso é um processo que não é de desmanchar os avanços que o SUS já teve ou inventar moda. Esses dois aspectos - reversão do subfinanciamento e investimento maciço na atenção primária - devem incidir na capacitação e na construção de um plano de cargos, carreiras e salário para todos os profissionais inseridos na atenção primária, para conseguir que todos os profissionais estejam naquele território corriqueiramente, cumprindo com suas obrigações. Nós precisamos também das práticas integrativas. Dentro do SUS passa, por dia, 1 milhão de usuários. Dessa parcela, nós temos um percentual considerável que são aqueles usuários que não querem remédio. Eles querem ser ouvidos, estão com a chamada dor da alma, querem ter a sua dignidade como usuário aceita pelos profissionais que lá estão, para que ele possa descarregar suas adversidades do campo mental, social, familiar. Enfim, é preciso que o sistema esteja preparado para isso.

JORGE: Se a Reforma Sanitária fosse minha, eu investiria na construção de um SUS exclusivamente público, onde saúde deixasse de ser vista como uma mercadoria ou como um produto a ser ofertado. E esse sistema deveria estar integrado à educação, à assistência social, atuando em rede, avançando na questão da determinação social da saúde e da doença, buscando uma maior qualidade de vida para a população. Deixando de ser um sistema voltado pura e simplesmente para o atendimento e, principalmente, o atendimento de emergência, porque é onde o gestor investe porque dá visibilidade política. Ninguém se preocupa se a atenção primária está fazendo a educação popular em saúde, a promoção e a prevenção corretamente. O gestor público faz como portfólio de atuação em saúde a questão da fila no hospital. E a fila do hospital só interessa a quem quer que o sistema seja comandado pelo caos, a quem quer subfinanciar o sistema, a quem é financiado pela iniciativa privada em suas campanhas eleitorais. Há uma construção de uma privatização das mentalidades, e isso fica bastante explícito com relação ao SUS. Se a Reforma Sanitária fosse minha, seria realmente bem definida a parcela de investimento de cada ente da administração pública e a revogação da Emenda Constitucional $95^{5}$. Não há possibilidade de um SUS público universal com a Emenda do teto de gasto. Não há possibilidade de qualquer discussão com relação à educação, à saúde, ao meio ambiente, enfim, com relação à vida da população com a presença dessa Emenda, porque ela é a PEC da morte. Ela vai causar, ao longo de 20 anos, a destruição e a morte dos mais pobres. Ela é a representação viva da necropolítica.

\section{Colaboradores}

Siqueira AG (0000-0003-3188-8922)*, Assis JBE (0000-0002-1672-9643)* e Souza W (0000-0003-3690-6595)* foram entrevistados por Nadais JAS (0000-0002-46966607)*. 


\section{Referências}

1. Brasil. Lei $n^{\circ} 11.350$, de 5 outubro de 2006. Regulamenta o $₫ 5^{\circ}$ do art. 198 da Constituição, dispõe sobre o aproveitamento de pessoal amparado pelo parágrafo único do art. $2^{\circ}$ da Emenda Constitucional $\mathrm{n}^{\circ} 51$ de 14 de fevereiro de 2006 , e dá outras providências. Diário Oficial da União. 6 Out 2006.

2. Brasil. Emenda Constitucional $n^{\circ} 51$, de 14 de fevereiro de 2006. Acrescenta os $\$ 94^{\circ}, 5^{\circ}$ e $6^{\circ}$ ao art. 198 da Constituição Federal. Diário Oficial da União. 15 Fev 2006

3. Paraíba. Lei n ${ }^{\circ}$ 2.107, de 15 de setembro de 1994. Institui o Conselho Municipal de Saúde-CMS, Revoga Decretos, e dá outras Providências. Diário Oficial de Patos. 16 Set 1994.

4. Brasil. Lei $\mathrm{n}^{\mathrm{0}} 13.595$, de 5 de janeiro de 2018. Altera a Lei $\mathrm{n}^{\circ} 11.350$, de 5 de outubro de 2006, para dispor sobre a reformulação das atribuições, a jornada e as condições de trabalho, o grau de formação profissional, os cursos de formação técnica e continuada e a indenização de transporte dos profissionais Agentes Comunitários de Saúde e Agentes de Combate às Endemias. Diário Oficial da União. 6 Jan 2006.

5. Brasil. Emenda Constitucional $\mathrm{n}^{\circ} 95$, de 15 de dezembro de 2016. Altera o Ato das Disposições Constitucionais Transitárias, para instituir o Novo Regime Fiscal, e dá outras providências. Diário Oficial da União. 6 Jan 2006.

Recebido em 19/07/2019

Aprovado em 18/11/2019

Conflito de interesse: inexistente

Suporte financeiro: não houve 